\title{
Uterine artery Doppler as a predictor of pre eclampsia - hospital based study
}

\author{
Neela Aruna Rekha ${ }^{1}$, Babu M.S ${ }^{2}$, Ashwani $\mathbf{N}^{3}$, Reddy S.R ${ }^{4}$ \\ ${ }^{1}$ Dr. Neela Aruna Rekha, Assistant Professor of Gynaecology and Obstetrics, Niloufer Hospital, Osmania Medical \\ College, Hyderabad, ${ }^{2}$ Dr. Mendu Suresh Babu, Assistant Professor of Pediatrics, Niloufer Hospital, Osmania Medical \\ College, Hyderabad, ${ }^{3}$ Dr. Neetika Ashwani, SNCU, Niloufer Hospital, Osmania Medical College, Hyderabad, \\ ${ }^{4}$ Dr. S. Rani Reddy, Professor of Gynaecology and Obstetrics, Gandhi Medical College, Hyderabad, India.
}

Address for Correspondence: Dr. Neela Aruna Rekha, Email: drarunarekha2015@gmail.com

\begin{abstract}
Aim: Study of early second trimester (13-16wks) uterine artery Doppler as predictor of pre eclampsia. Objective: To study whether early changes in uterine artery Doppler have better predictive value for preeclampsia as compared to gestational hypertension. To analyze the maternal and fetal outcome in cases with pre eclampsia vs gestational hypertension. Material \& Methods: From 2009 to 2011, we conducted an institutional based study among 100 pregnant women. Uterine artery Doppler was done in the women in early second trimester during the antenatal visits at Niloufer Hospital. We measured and recorded the BP, urine analysis, complete blood work done in every antenatal visit. These women were followed up to their delivery. Data were analyzed and $\mathrm{p}<0.05$ was considered significant. Results: Pre eclampsia developed in $31.25 \%$ of the pregnant women with bilateral uterine artery notching at 13-16 weeks of gestational age Odds ratio of patients developing hypertension with uterine artery notching is 6.6. Chi-square $=11.8, \mathrm{P}$ value $<0.0005$ (significant). This study has a sensitivity of $71.42 \%$, specificity of $74.41 \%$, positive predictive value of $31.25 \%$ and negative predictive value of $94.11 \%$ in predicting onset of preeclampsia in pregnancy. Conclusion: Uterine artery Doppler should be done routinely in all pregnant women as risk factors can be identified at an early stage where timely intervention can reduce the maternal and neonatal complications.
\end{abstract}

Keywords: Uterine artery Doppler, Pre eclampsia, Gestational hypertension, Early second trimester

\section{Introduction}

Hypertensive disorders are the most common medical complications of pregnancy $(7.15 \%)$ and a major cause of maternal morbidity and mortality $(30 \%)$ and fetal mortality and morbidity $(22 \%)[1]$.

Clinically, classification of hypertension in pregnancy differentiates between gestational hypertension and preeclampsia based upon the presence of proteinuria [2]. The outcome of pregnancy in terms of maternal morbidity and mortality, fetal morbidity and mortality has shown to be far better with gestational hypertension as compared to preeclampsia this is because it has been postulated that etiopathogenesis of two conditions are distinct [3]. In preeclampsia incomplete trophoblast

Manuscript received $6^{\text {th }}$ August 2016

Reviewed: $20^{\text {th }}$ August 2016

Author Corrected: $4^{\text {th }}$ September 2016

Accepted for Publication $19^{\text {th }}$ September 2016 invasion in the early second trimester with insufficient changes of the uterine and uteroplacental circulation into a low impendence system has been proposed as a pathophysiological mechanism for the development of preeclampsia.

This abnormal placentation is reflected in the reduced diastolic flow in uterine arteries as evidenced by diastolic notching in the uterine artery wave form [3].

With the use of Doppler technology, a non invasive technique for evaluating the uterine and uteroplacental circulation, it has been possible to show a strong positive correlation between uterine vascular resistance expressed by persistence of an early diastolic notch in the Doppler waveform and onset of preeclampsia. Doppler waveform - uterine artery notching - has been 
reported to be associated with subsequent increased risks for preeclampsia or growth restricted infants [4,5].

The purpose of this study is to evaluate the predictive value of uterine artery doppler with regard to the development of preeclampsia and to compare the maternal and fetal outcomes in gestational hypertension and pre eclamsia.

\section{Materials and Methods}

Study Group: Hundred pregnant women (primis and multis), attending antenatal outpatient department without previous record of hypertension or renal disease were studied.

Women with twin pregnancy, obesity, placenta previa, previous history of bleeding disorders, thrombotic disorders and fetal anomalies, were excluded from the study.

Period of Study: The study was conducted at Niloufer Hospital for women and children, Osmania Medical College, Hyderabad from October 2014-September 2015.

Method: Hundred pregnant women attending antenatal outpatient department underwent bilateral uterine artery Doppler investigation at $13-16$ weeks of gestation.

Uterine artery Doppler was performed during second trimester by means of a color Doppler power vision 6000 (THOSHIBA Corp, TOKYO, JAPAN) using a 3.5 $-5 \mathrm{MHz}$ transabdominal transducer.

Patients were examined in a semirecumbent position.

The recording was performed at the apparent crossover point of the uterine and internal iliac arteries, after identification of the main uterine artery on a longitudinal scan lateral to the uterus.

The presence of an early diastolic notch on both sides of the uterine artery waveforms was recorded.
At every antenatal visit, urine was tested for protein and blood pressure recordings were taken. Further analysis was done dividing patients as normotensive and those patients developing hypertension after 20 weeks of gestation.

Hypertension was defined as blood pressure of at least 140/90 $\mathrm{mm}$ of $\mathrm{Hg}$, two measurements four hours apart.

Hypertension was classified either as preeclampsia or gestational hypertension following the criteria defined by the report of the National Blood Pressure Education Programme (2000) [2].

Maternal monitoring included blood pressure measurements, Hemoglobin platelets, uric acid, liver enzymes; renal function tests were checked twice a week. None of the patients were on antihypertensive drugs at the time of first Doppler evaluation.

In women with hypertension Antenatal fetal surveillance included NST, MBPP twice weekly starting at 32 weeks.

Antihypertensive drugs used were oral nefidepine 30$120 \mathrm{mg} /$ day, alpha methyl dopa $250 \mathrm{mg}$ or $500 \mathrm{mg}$ tid, oral or iv Labetalol. Magnesium sulfate was used when patient developed imminent signs and symptoms of eclampsia.

Biochemical tests for CBP with platelets, LFT and RFT are done at weekly intervals in patients managed conservatively till $34-36$ wks of gestation. They were followed till delivery and maternal and fetal outcome were analyzed.

Patients were reviewed at $2 \mathrm{wks}$, $6 \mathrm{wks}$ and $12 \mathrm{wks}$ following delivery for persistence of hypertension. Chisquare test was used for comparison of frequencies.

A p value below or equal to 0.05 was considered to be statistically significant for a $95 \%$ CI. The data were analyzed through SPSS 10.0 (SPSS Inc.)

\section{Results}

Figure-1: Flow chart - distribution of 100 pregnant women attending antenatal OP who were investigated by uterine artery Doppler at 13-16wks.

In our study age wise distribution of pregnant women who developed pre-eclampsia in less than 20 years was 2 and between 20-25 years were 14 where as only 2 women in 20-25 age had developed Gestational hypertension. 


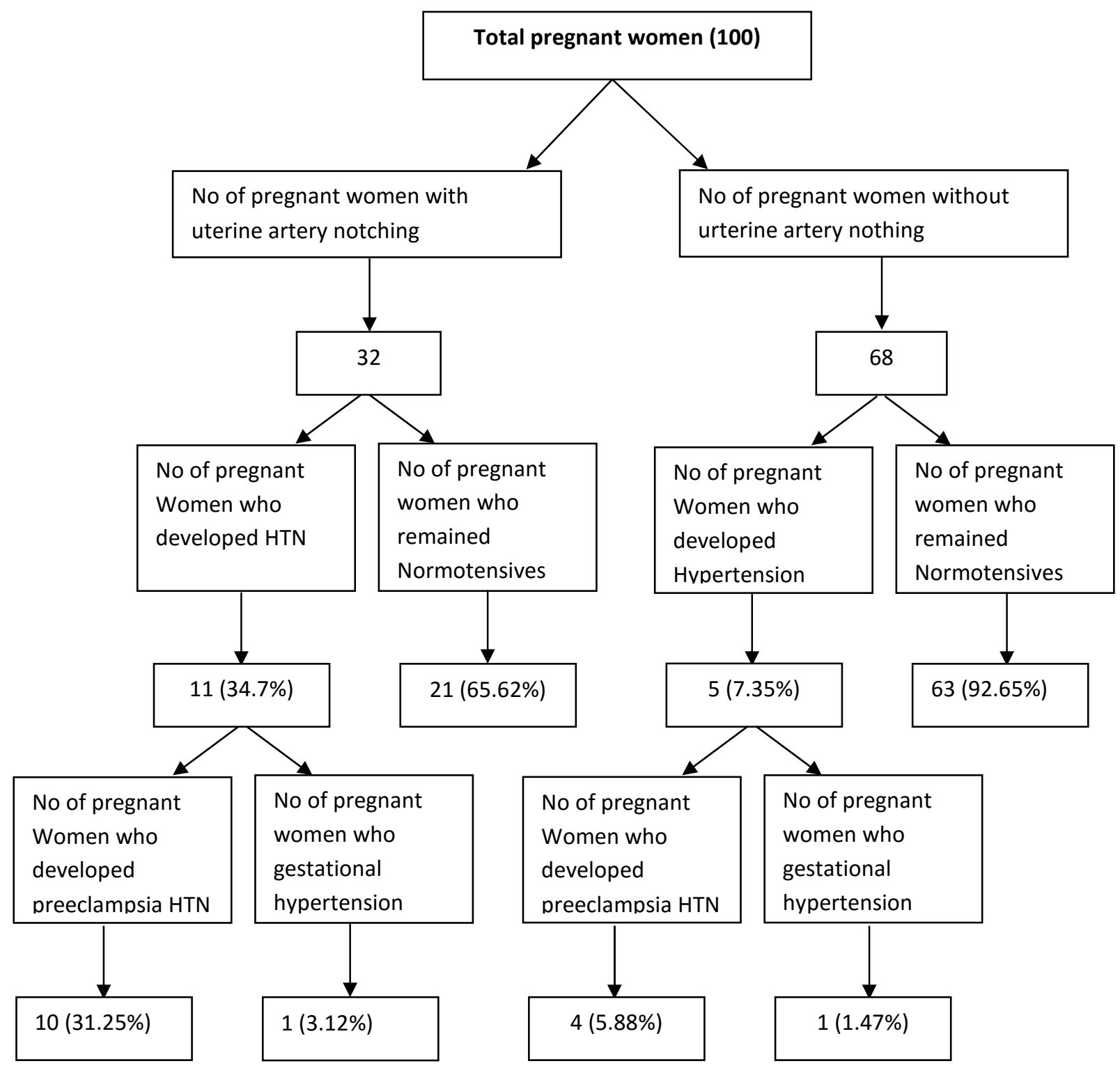

Figure-1: depicts the study procedure and stages with outcome of the study

Table-1: Distribution of pregnant women with uterine artery notching according to age $(n=32)$.

\begin{tabular}{|c|c|}
\hline Age & No. of pregnant women with uterine artery notching \\
\hline$<20 \mathrm{yrs}$ & $3(9.37 \%)$ \\
\hline $20-25 \mathrm{yrs}$ & $29(90.62 \%)$ \\
\hline
\end{tabular}

There is no significance (Yates corrected $\mathrm{x}^{2}=0.36(\mathrm{P}>0.05)$ ) among age of pregnant women with uterine artery notching (Table 1).

Women developed pre-eclampsia are primigravida with significance (Yates corrected $\mathrm{x}^{2}=10.90, \mathrm{P}<0.004$ significant). Only 2 multigravida women developed pre-eclampsia and 4 gestational hypertension.

Thirty primigravida women were found to have uterine artery notching and only 2 multigravida had notching . 
Table-2: No. of women who developed pre-eclampsia and gestational hypertension with and without uterine artery notching $(n=16)$.

\begin{tabular}{|c|c|c|}
\hline & With uterine artery notching $(\mathbf{n}=11)$ & Without uterine artery notching $(\mathbf{n}=5)$ \\
\hline Pre-eclampsia & $10(31.25 \%)$ & $4(5.88 \%)$ \\
\hline Gestational Hypertension & $1(3.12 \%)$ & $1(1.47 \%)$ \\
\hline
\end{tabular}

Odds ratio for women who developed pre-eclampsia and gestational hypertension with and without uterine artery notching is 2.5. Yates corrected $\mathrm{x}^{2}=0.04(\mathrm{P}<0.05)$ significant (Table 2).

Table-3: Maternal and Neonatal complications in women with uterine artery notching.

\begin{tabular}{|c|c|c|}
\hline Maternal & With hypertension & Without hypertension \\
\hline Abruption & 3 & - \\
\hline Eclampsia & 1 & Without hypertension \\
\hline Neonatal & With hypertension & - \\
\hline MAS & - & 3 \\
\hline IUGR & 8 & - \\
\hline RDS & - & - \\
\hline IUD & 3 & \\
\hline
\end{tabular}

The neonatal outcome significantly was affected by presence of uterine artery notching than in the absence of hypertension.

There is higher rate of NICU admission of babies with uterine artery notching and hypertension. Eight babies with hypertensive mothers were admitted in the NICU compare to 3 babies with non hypertensive mothers. Yates corrected $\mathrm{x}^{2}=13.67(\mathrm{P}<0.0002)$ significant (Table 3$)$.

Table-4: Gestational age at which hypertension developed among pregnant women with uterine artery notching.

\begin{tabular}{|c|c|}
\hline Gestational age in weeks & No. of women developed Hypertension. \\
\hline $20-28$ weeks & $8(72.72 \%)$ \\
\hline $29-36$ weeks & $3(27.27 \%)$ \\
\hline
\end{tabular}

When uterine artery diastolic notching is present women developed hypertension at an earlier gestational age (Table 4).

Table-5: Gestational age at which the pregnant women delivered with uterine artery notching $(\mathbf{n}=32)$.

\begin{tabular}{|c|c|c|}
\hline Gestational age in weeks & $\begin{array}{c}\text { No. of pregnant women with } \\
\text { hypertension }\end{array}$ & $\begin{array}{c}\text { No. of pregnant women without } \\
\text { hypertension }\end{array}$ \\
\hline$<34$ weeks & $10(90.9 \%)$ & $2(9.52 \%)$ \\
\hline$>34$ weeks & $1(9.09 \%)$ & $19(90.47 \%)$ \\
\hline
\end{tabular}

Odds ratio for women with uterine artery notching and without uterine artery notching is 8.16. As Hypertension develops at earlier gestational age in women with uterine artery notching incidence of preterm delivery is high. Yates corrected $\mathrm{x}^{2}$ $=17.08 \mathrm{P}<0.000059$ significant (Table 5).

Five pregnant women more than 34 weeks gestation delivered with hypertension and without uterine artery notching. Women who developed hypertension without uterine artery notching has low incidence of preterm deliveries. 
Odds ratio of patients developing hypertension with uterine artery notching is 6.6. Chi-square $=11.8, \mathrm{P}$ value $<0.0005$ (significant). Bilateral uterine artery notching at $13-16$ wks of gestational age has $71.42 \%$ sensitivity, $74.41 \%$ specificity, $31.25 \%$ positive predictive value and $94.11 \%$ negative predictive value for pre-eclampsia (Table 6).

Table-6: Bilateral uterine artery notching at 13-16weeks.

\begin{tabular}{|c|c|}
\hline Sensitivity & Specificity \\
$71.42 \%$ & $74.41 \%$ \\
\hline Positive Predictive Value & Negative Predicitve Value \\
$31.25 \%$ & $94.11 \%$ \\
\hline
\end{tabular}

\section{Discussion}

Hypertensive disorders complicating pregnancy cause maternal mortality, morbidity and fetal mortality, morbidity. Preeclamsia is a complex clinical syndrome involving multiple organ system. The search for an ideal predictive test and preventive measures remains challenging.

In 7 of the 13 studies analyzed $[6,7,8,9,10,11,12]$ uterine artery was found to be suitable screening tool. Three studies [13, 14, 15] were inconclusive. While three studies $[16,17,18]$ showed that uterine artery Doppler is of no value in predicting onset of preeclampsia.

In our study of 100 pregnant women, pre eclampsia developed in $31.25 \%$ of the pregnant women with bilateral uterine artery notching at 13-16 weeks of gestational age, sensitivity of the test is $71.42 \%$, specificity is $74.41 \%$, Positive predictive value is $31.25 \%$, negative predictive value is $94.11 \%$.

Our study results are comparable to study of Gupta Shashi et al [19] in 2009 study of 88 women with bilateral uterine notch at 12-16 weeks of gestation. Results shown that prelcampsia developed in $31.42 \%$, sensitivity is $68.75 \%$, specificity $66.6 \%$, positive predictive value $31.42 \%$, negative predictive value 90.5\%. Harrington K et al, in 1997 [20] described preclampsia in $15.16 \%$ of the women with bilateral uterine artery notch at $12-16$ weeks of gestation. His study showed increased risk of preclampsia, premature delivery and the delivery of a small for gestational age baby.

In our study, out of 100 women 14 developed preclampisa and 2 developed gestational hypertension with or without uterine artery notching. Poon L.C.Y. et al (2009) [21], examined 9149 singleton pregnancies and there were $8061(96.4 \%)$ cases unaffected by PE or $\mathrm{GH}, 165(2.0 \%)$ that developed PE including 37 that required delivery before 34 weeks (early PE) and 128 with late PE and $140(1.7 \%)$ that developed GH.

In our study of 100 pregnant women, 3 women who had gestational hypertension 1 women progressed to preeclampsia. Patrick Saudan et al [22] retrospective anlaysis, 416 women initially presented as having gestational hypertension progressed to preclampsia 62 $(15 \%)$. In the prospective study, 112 women initially presented with gestational hypertension and 29 progressed to preclampsia.

In women who developed hypertension $(n=16) 9$ babies developed intrauterine growth restriction, 2 babies developed meconium aspiration syndrome and respiratory distress syndrome, there were 3 intrauterine deaths. Agarwal et al [23] (2009) conducted a study on 53 women, 38 primiparas forming group I and 15 high risk pregnancies forming group II. Eight of the 38 in group I and nine of the 15 in group II showed persistence of bilateral notching. Of these seventeen, nine developed IUGR with PIH and 8 developed IUGR alone. A higher percentage of preeclamptic women developed IUGR and neonatal complications, (11/14) $78.57 \%$ as compared to women with gestational hypertension $(1 / 2) 50 \%$.

\section{Conclusions}

1. Women who developed hypertension with uterine artery notching had more maternal and neonatal complications compared to women who developed hypertension without uterine artery notching reflecting the early onset of placental pathology. Women with pre eclamsia had more maternal and neonatal complications compared to women with gestational hypertension. 
2. Based on our results, primigravida were found more prone to hypertension. Hence, we recommend early uterine artery Doppler to predict pre eclampsia and follow up and can decrease maternal and neonatal complications.

3. Routine BP monitoring should be done at primary health center and should be referred to tertiary center early if any intervention is required.

4. Administration of low dose aspirin increased calcium intake, antioxidant and nitric oxide usage can be instituted to prevent or arrest the progress of the disease and improve maternal and neonatal outcome.

5. We conclude, early second trimester uterine artery Doppler should be included as a routine investigation in high risk pregnancies.

6. In the future the results of this study can be extrapolated to show the efficacy of preventive measures taken early in pregnancy in women who have bilateral uterine notch.

Funding: Nil, Conflict of interest: None initiated, Permission from IRB: Yes

\section{References}

1. Sibai, B., Dekker, G. and Kupferminc, M. Preeclampsia. Lancet. 2005 Feb 26-Mar 4;365(9461): 785-99. DOI: 10.1016/S0140-6736(05)17987-2.

2. Report of the National high blood pressure education program working group on high blood pressure in pregnancy. Am J Obstet Gynecol. 2000 Jul; 183(1): S1-S22.

3. Redman CW, Sargent IL. Preeclampsia and the systemic inflammatory response. Semin Nephrol. 2004 Nov;24(6):565-70.

4. Fleischer A, Schulman H, Farmakides G, Bracero L, Grunfeld L, Rochelson B, et al. Uterine artery Doppler velocimetry in pregnant women with hypertension. Am J Obstet Gynecol. 1986 Apr;154(4):806-13.

5. Groom KM, North RA, Stone PR, Chan EH, Taylor RS, Dekker GA, et al: Patterns of change in uterine artery doppler studies between 20 and 24 weeks of gestation and pregnancy outcome. Obstet Gynecol. 2009Feb;113(2Pt1):332-8.doi:10.1097/AOG. 0b013e $318195 \mathrm{~b} 223$.
6. Arduini D, Rizzo G, Romanini C, Mancuso S. Uteroplacental blood flow-velocity waveforms as predictors of pregnancy-induced hypertension. Eur J Obstet Gynecol Reprod Biol. 1987 Dec;26(4):335-41.

7. Bower S, Bewley S, Campbell S. Improved prediction of preeclampsia by two-stage screening of uterine arteries using the early diastolic notch and color Doppler imaging.Obstet Gynecol. 1993 Jul;82(1): 78-83.

8. Campbell S, Pearce JM, Hackett G, Cohen-Overbeek T, Hernandez C. Qualitative assessment of uteroplacental blood flow: an early screening test for highrisk pregnancies. Obstet Gynecol. 1986 Nov;68(5): 649-53.

9. Harrington KF, Campbell S, Bewley S, Bower S. Doppler velocimetry studies of the uterine artery in the early prediction of preeclampsia and intra-uterine growth retardation. Eur J Obstet Gynecol Reprod Biol. 1991 Dec;42 Suppl:S14-20.

10. Harrington K, Cooper D, Lees C, Hecher K, Campbell S. Doppler ultrasound of the uterine arteries: the importance of bilateral notching in the prediction of pre-eclampsia, placental abruption or delivery of a small-for-gestational-age baby. Ultrasound Obstet Gynecol. 1996 Mar;7(3):182-8.

11. Schulman H, Winter D, Farmakides G, Ducey J, Guzman E, Coury A, et al. Pregnancy surveillance with Doppler velocimetry of uterine and umbilical arteries. Am J Obstet Gynecol. 1989 Jan;160(1):192-6.

12. Valensise H, Bezzeccheri V, Rizzo G, Tranquilli AL, Garzetti GG, Romanini C. Doppler velocimetry of the uterine artery as a screening test for gestational hypertension. Ultrasound in Obstet Gynecol. 1993 Jan $1 ; 3(1): 18-22$.

13. Bewley S, Cooper D, Campbell S. Doppler investigation of uteroplacental blood flow resistance in the second trimester: a screening study for preeclampsia and intrauterine growth retardation. $\mathrm{Br} \mathbf{J}$ Obstet Gynecol. 1991 Sep;98(9):871-9.

14. Hanretty KP, Primrose MH, Neilson JP, Whittle MJ. Pregnancy screening by Doppler uteroplacental and umbilical artery waveforms. Br J Obstet Gynecol. 1989 Oct;96(10):1163-7. 
15. Jacobson SL, Imhof R, Manning N, Mannion V, Little D, Rey E, et al. The value of Doppler assessment of the uteroplacental circulation in predicting preeclampsia or intrauterine growth retardation. Am J Obstet Gynecol. 1990 Jan;162(1):110-4.

16. Davies JA, Gallivan S, Spencer JA. Randomized controlled trial of Doppler ultrasound screening of placental perfusion during pregnancy. Lancet. 1992 Nov 28;340(8831):1299-303.

17. Newnham JP, Patterson LL, James IR, Diepeveen DA, Reid SE. An evaluation of the efficacy of Doppler flow velocity waveform analysis as a screening test in pregnancy. Am J Obstet Gynecol. 1990 Feb;162 (2):403-10.

18. North RA, Ferrier C, Long D, Townend K, KincaidSmith P. Uterine artery Doppler flow velocity waveforms in the second trimester for the prediction of preeclampsia and fetal growth retardation. Obstet Gynecol. 1994 Mar; 83(3):378-86.

19. Gupta S, Gupta PK, Bodani P, Khamesra A. Transvaginal Doppler of uteroplacental circulation in early prediction of pre-eclampsia by observing bilateral uterine artery notch and resistance index at 12-16 wks of gestation. J Obstet Gynecol India. 2009 Nov/Dec; 59(6):541-546.

20. Harrington K, Carpenter RG, Goldfrad C, Campbell S. Transvaginal Doppler ultrasound of the uteroplacental circulation in the early prediction of preeclampsia and intrauterine growth retardation. $\mathrm{Br} \mathrm{J}$ Obstet Gynecol. 1997 Jun;104(6):674-81.

21. Poon LC, Karagiannis G, Leal A, Romero XC, Nicolaides KH. Hypertensive disorders in pregnancy: Screening by uterine artery Doppler imaging and blood pressure at 11-13 weeks. Ultrasound Obstet Gynecol. 2009 Nov;34(5):497-502. doi: 10.1002/uog.7439.

22. Saudan P, Brown MA, Buddle ML, Jones M. Does gestational hypertension become pre-eclampsia?. Br J Obstet Gynecol. 1998 Nov;105(11):1177-84.

23. Agrawal P, Agrawal RK, Agrawal MC. Persistent uterine artery notch- A predictor of intrauterine growth retardation and pregnancy induced hypertension. J Obstet Gynecol India. 2006 Jul/Aug;56(4):301-303.

\section{How to cite this article?}

Neela Aruna Rekha, Babu M.S, Ashwani N, Reddy S.R. Uterine artery Doppler as a predictor of pre eclampsia - hospital based study. Int J Med Res Rev 2016;4(9):1655-1661.doi:10.17511/ijmrr. 2016.i09.24. 